\title{
Confiabilidad de los resultados preliminares del XI Censo General de Población y Vivienda de 1990
}

\section{Rodolfo Corona Vázquez*}

\begin{abstract}
Este trabajo tiene como objetivo establecer algunos parámetros de referencia sobre la confiabilidad que pueden tener los resultados preliminares del XI Censo General de Población y Vivienda de 1990, realizado en México del 12 al 16 de marzo de ese año. Para el efecto se incluyen cinco secciones: en la primera se mencionan aspectos globales sobre la importancia de los censos y la necesidad de que sean evaluados. La segunda se dedica a mostrar lo que es un proceso de evaluación censal y los elementos que involucra. En la tercera sección se determinan las principales características de las evaluaciones realizadas sobre los últimos censos mexicanos. La cuarta aborda especificamente el censo de 1990, señalando entre otras cosas los posibles niveles de confiabilidad de sus resultados preliminares; en esta parte, y después de comparar tales resultados con diversas estimaciones [elaboradas con ese propósito] y proyecciones, y en general con el conocimiento que se tiene de la dinámica demográfica mexicana, se establece que el XI Censo omitió en su conteo cuando menos a dos millones de personas. La quinta sección, por último, contiene un análisis de los comentarios y críticas que han surgido en la prensa nacional en torno a la exactitud del censo de 1990.
\end{abstract}

\section{Utilidad y exactitud de un censo de población}

Un censo de población es considerado como una fotografía estadística porque es un proceso de generación de datos demográficos, económicos y sociales de los habitantes de un país en relación con un momento determinado.

Debido a sus características de universalidad, simultaneidad e individuo como unidad de medida, y a los fenómenos que cuantifica (actividad económica, escolaridad, sexo, edad, etc.), un censo constituye generalmente la fuente de datos más importante de todo sistema nacional de información. Tal importancia se manifiesta a través de su utilidad como base cuantitativa y punto de referencia, a veces único, para conocer los niveles de vida de la

* El Colegio de la Frontera Norte. 
propia población, para el desarrollo de investigaciones científicas, para un sinnúmero de propósitos gubernamentales (la estructuración de planes y programas oficiales entre otros) y para producir otras estadísticas (como las derivadas de encuestas por muestreo].

La importancia y utilidad de un censo se encuentran supeditadas, sin embargo, a la veracidad con que sus resultados representan las cantidades y aspectos poblacionales que teóricamente documentan. Esto obedece a que la validez de cualquier indicador, análisis o diagnóstico derivado de un dato censal se encuentra condicionada por la exactitud del propio dato; exactitud que depende del cumplimiento de tres condiciones. La primera, que exista una total cobertura; es decir, que respecto a un cierto momento hayan sido contados todos los habitantes del territorio en cuestión, pero una sola vez cada uno de ellos. Segunda, que hayan sido exitosos tanto el diseño como la captación conceptuales; o sea, la correcta identificación de la categoría a que pertenece cada individuo respecto a las variables que se documentan [sexo, edad, nivel educativo, participación económica, condición migratoria, estado civil, distribución geográfica de las personas de acuerdo con su lugar de residencia o presencia, etc.). Y tercera condición, la no existencia de errores en la elaboración propiamente tal de los datos, desde su acopio en el cuestionario o boleta hasta la presentación final de las cifras resultantes.

Otro elemento también asociado a la utílidad de un censo consiste en el grado de adecuación de la realidad que requiere cuantificarse con algunos rasgos del censo, como la definición de la población a ser cubierta, su contenido en términos de variables y clasificaciones y la fecha de levantamiento. Este elemento, aunque en principio ajeno a la exactitud y a la realización de las actividades operativas de un censo, se encuentra vinculado a su diseno y en buena parte determina su aprovechamiento, pues en la medida en que un censo no haya documentado los fenómenos demográficos y socioeconómicos de mayor interés, sus resultados serán poco empleados y, en consecuencia, sustituidos por estadísticas más apropiadas.

\section{Evaluación de un censo de población}

Para establecer la confiabilidad o exactitud de un censo es necesario sujetarlo a una evaluación, en la que se establecen su nivel de cobertura y la calidad de sus resultados, lo que equivale a determinar la medida en que se cumplieron las tres condiciones ya men- 
cionadas. Además, la misma evaluación suministra lineamientos para modificar o ajustar los datos, en caso de que éstos contengan errores. ${ }^{1}$

Una evaluación es una especie de investigación conformada por tres tipos complementarios de análisis sobre la información censal: el conceptual, el referido al proceso de generación de los datos y el numérico.

El primero, análisis conceptual, se orienta a indagar el alcance temático, espacial y temporal de las definiciones y conceptos empleados, así como la medida en que dicho alcance cubre o cumple con los objetivos del censo.

El análisis del proceso de generación se dirige a la búsqueda del origen o causas de los errores en los datos, errores que pueden producirse en el transcurso del proceso mismo de elaboración de los resultados censales, desde su planeación y determinación de requerimientos de información, hasta el levantamiento, captura y tratamiento de las cifras estadísticas. Por ello, este análisis consiste básicamente en el examen detallado de la documentación existente sobre la realización del censo.

El análisis numérico, por su parte, tiene como propósito la detección de errores y la identificación de la magnitud y el sentido de los mismos. Para el efecto, y empleando diversos procedimien. tos y métodos estadísticos y demográficos, se revisan críticamente tanto los resultados finales [esto es, las tabulaciones con datos censales) como los archivos y la propia información original o cuestionarios, los cuales se examinan comparando con otros registros sobre los mismos individuos o efectuando reentrevistas.

El análisis numérico, pero sobre los datos tabulados [o resultados finales), es lo que usualmente se entiende por evaluación censal, y en general se lleva a cabo realizando confrontaciones de los datos censales en sí mismos, lo que se denomina análisis de consistencia interna, y de ellos con otros conjuntos de cifras teórica o empíricamente relacionados con los temas y conceptos abarcados en el censo. ${ }^{2}$ Estos contrastes numéricos se realizan en forma directa y mediante la aplicación de técnicas estadísticas y demográficas especiales, y como resultado se detectan y cuantifican discrepancias que pueden ser atribuidas a errores en la informa-

\footnotetext{
1 Una explicación detallada del proceso de evaluación de datos censales se encuentra en Rodolfo Corona, Alberto Minujin y Gabriel Vera (1982).

2 Dependiendo de la naturaleza de las cifras de referencia, a estos contrastes de los datos censales se les llama análisis de comparabilidad espacial, temporal, con otras fuentes de datos o contra configuraciones teóricas.
} 
ción o al comportamiento propio y esperado del fenómeno bajo estudio.

\section{Las evaluaciones de los censos mexicanos}

En México se han realizado evaluaciones de los censos de población por lo menos a partir del levantado en 1950. En general, puede decirse que las evaluaciones llevadas a cabo han sido parciales porque se han dedicado a examinar sólo uno de los temas incluidos en la boleta, como el número de habitantes del país (únicamente o junto con su distribución por sexo y edad) o la participación económica, la mortalidad, la fecundidad o las migraciones; o bien, evaluaciones parciales por tener como objetivo la revisión de algún aspecto del trabajo censal, como la organización conceptual, la enumeración de personas o la captura y procesamiento de datos. ${ }^{3}$

Además de ser parciales, las evaluaciones de los censos mexicanos tienen dos particularidades. Por un lado, que en proporción mayoritaria se han dedicado a establecer la cobertura general del censo y, por otro, que hay una notable ausencia de evaluaciones a un nivel geográfico diferente del nacional.

La inexistencia virtual de exámenes críticos de los resultados censales para regiones, entidades federativas, municipios y ciudades tiene su razón de ser en el enorme aumento de las dificultades para efectuar la evaluación, dificultades que se encuentran tanto en relación con la información estádística como en la superior complejidad del comportamiento demográfico en zonas más reducidas.

En cuanto a la información, los problemas adicionales son de dos tipos: uno, la menor disponibilidad de estadísticas para efectuar las confrontaciones [cifras sobre emigrantes internacionales por lugar de origen, como ilustración) y, otro, el aumento de las fallas en los datos para estos ámbitos espaciales; por ejemplo, las defunciones erróneamente asignadas en otro municipio provocan sobre y subregistro en las áreas involucradas. Respecto a las dificultades causadas por la dinámica poblacional, lo más importante

\footnotetext{
${ }^{3}$ El ejemplo más completo sobre las diversas evaluaciones efectuadas a los censos mexicanos lo constituye el conjunto de ponencias presentadas al Taller $\mathrm{Na}$ cional de Evaluación del Censo General de Población y Vivienda, 1980, organizado en 1986 por el Instituto Nacional de Estadística, Geografía e Informática (INEGI). Estas ponencias fueron publicadas en dos volúmenes que contienen un total de 2182 páginas (véase INEGI, 1986).
} 
es la aparición de otra variable: la migración interna, cuyas modalidades no son del todo conocidas y mucho menos han sido cuantificadas.

La falta de evaluaciones para áreas especfficas, como estados o zonas metropolitanas, ha traído como consecuencia el supuesto de que el grado de cobertura global de los censos es compartido por igual en todas las partes de lä república, lo que dista mucho de cumplirse estrictamente porque el operativo censal no es homogéneo, porque las diferencias culturales y de otra naturaleza entre los habitantes de distintas zonas impiden idénticas respuestas ante las mismas preguntas, y porque existe una gran variedad de situaciones relativas a la movilidad espacial de la población que dificultan, de manera diferencial para una y otra región del país, la identificación del lugar preciso de residencia. En otras palabras, el nivel general de omisión de un censo es un promedio no necesariamente aplicable en cada región del territorio nacional.

Lo anterior resulta de especial importancia en el caso del X Censo, el levantado en 1980, pues en esa ocasión se utilizó una definición de residencia habitual de difícil aplicación, con problemas para abarcar todos los casos y con la tendencia a provocar sobre o subestimaciones de población en las zonas fuertemente afectadas por el fenómeno migratorio, en particular donde ocurren desplazamientos temporales, como la Zona Metropolitana de la Ciudad de México (ZMCM), las ciudades de la frontera norte o las áreas rurales caracterizadas por recibir o enviar trabajadores agrícolas. ${ }^{4}$

De esta suerte, con seguridad los datos censales de 1980 contienen inexactitudes en cuanto a la distribución geográfica de los habitantes del país, inexactitudes que para algunas áreas representan niveles de omisión muy diferentes al promedio nacional [inclusive con sentido o signo opuesto) y que se traducen en cifras menores o mayores de población respecto a sus verdaderos residentes en esa época.

Esta situación adquiere todavía mayor relevancia al considerar que el concepto de residencia habitual usado en 1980 es distinto a los empleados en los censos precedentes y en el realizado en 1990. Por ello, debe tenerse cuidado al relacionar los datos del censo de 1980 con los de otros años, pues la incomparabilidad conceptual puede acarrear indicaciones falaces sobre el ritmo de crecimiento de algunas zonas, especialmente de aquellas que se

\footnotetext{
4 Un examen detallado de los problemas del concepto de población residente utilizado en el Censo General de Población y Vivienda de 1980 se encuentra en Rodolfo Corona (1986 y 1988).
} 
vieron más afectadas por los errores al definir y aplicar el concepto de residencia en el $\mathrm{X}$ Censo. ${ }^{5}$

En cuanto al conjunto de las evaluaciones sobre los cuatro censos mexicanos de 1950 a 1980, también se mencionó que la gran mayoría se han orientado a establecer el grado de cobertura censal para el total de la población del país clasificada por sexo y edad. Este hecho se debe básicamente a tres motivos. ${ }^{6}$ Primero, que el grado de cobertura total (entendido como porcentaje de mexicanos omitidos en el recuento) es el indicador más generalizado para calificar el desarrollo de todo el trabajo censal. Segundo, que los datos de población por edad y sexo son los resultados fundamentales y de mayor uso de un censo. Y tercero, que el punto de partida de las proyecciones demográficas debe ser una serie de cifras que de la mejor manera posible represente a la real población por sexo y edad; por ello se usan como base los datos censales, pero corregidos o ajustados, lo cual implica la realización previa de una evaluación. En otros términos, las proyecciones necesariamente incluyen la revisión crftica de los resultados del censo inmediato anterior a su fecha de inicio.

Respecto a estas evaluaciones de la cobertura global de los censos nacionales conviene hacer otros dos señalamientos. Uno, que la mayor parte de las veces han sido elaboradas, en exclusiva o junto con otros organismos, por la propia institución que realiza el censo, esto es, por la Dirección General de Estadística, antes ubicada en la Secretaría de Industria y Comercio y ahora perteneciente al Instituto Nacional de Estadística, Geografía e Informática [INEGI]. Esto se explica por el elevado número de actividades que una evaluación involucra, ${ }^{7}$ por la disponibilidad irrestricta de los materiales, documentos y datos necesarios (en relación con el censo mismo y con otras fuentes de información); porque también esta dependencia pública ha sido la productora de las proyecciones consideradas como oficiales, aunque en la década pasada se le asignó esta tarea al Consejo Nacional de Población

\footnotetext{
${ }^{5}$ La detección de la incomparabilidad conceptual del Censo de 1980 con otros censos en cuanto a población residente, y los problemas que esto acarrea en especial para ciertas áreas del país, fue uno de los principales resultados de las evaluaciones citadas en la nota anterior.

6 También podría mencionarse otro elemento de importancia: la existencia de técnicas demográficas especialmente diseñadas para evaluar la omisión de población por sexo y edad.

7 Además, la realización de estas actividades es laboriosa y en algunos casos compleja, e implica la participación de distintos especialistas y el empleo de modernos equipos de cómputo electrónico.
} 
(Conapo), y porque como un elemento del propio trabajo censal se halla su validación.

El otro señalamiento sobre los procesos para evaluar la omisión de población nacional (por sexo y edad) en los censos mexicanos consiste en que éstos se han visto enriquecidos y mejorados con el paso del tiempo. Este avance obedece a varios factores, entre ellos: un acervo estadístico cada vez más extenso, detallado y confiable para llevar a cabo las comparaciones anotadas (diversas encuestas demográficas por muestreo, más censos previos, estadísticas vitales más oportunas y con menor subregistro); un notorio avance en los equipos de cómputo respecto a rapidez de procesamiento y capacidad en el manejo de grandes volúmenes de datos; un superior conocimiento de la evolución demográfica del país, junto con la existencia de modelos y técnicas más perfeccionados para el examen de irregularidades en los datos, y un progreso de los especialistas mexicanos en cuanto a capacitación formal y experiencia en este tipo de tareas.

Como consecuencia de lo anterior, las evaluaciones de la cobertura total de los censos son sin duda cada vez de mayor precisión. Además, las últimas evaluaciones tienen la ventaja de que, con la aplicación de un procedimiento llamado de conciliación censal, ponen en juego al mismo tiempo las diferentes estadísticas e indicadores que representan la dinámica poblacional de la república durante uno o varios periodos decenales, incorporando las cifras de dos o más censos; de tal suerte, se logran relacionar numéricamente los fenómenos de mortalidad, fecundidad y migración internacional con las existencias humanas al inicio y término de cada intervalo. Estas evaluaciones permiten entonces la corrección de los datos censales involucrados, en función de ellos mismos y de las estimaciones que se consideran más confiables sobre los niveles de incidencia de las variables demográficas que producen los crecimientos natural y social de todos los habitantes del país.

De esta manera, en la década de los ochenta se evaluaron conjuntamente los censos desde 1950 (o 1960) a 1980, obteniéndose indicadores comparables sobre la omisión censal de los mismos a nivel nacional. Además, un subproducto por demás importante de estas evaluaciones ha sido el establecimiento, bastante aproximado a la realidad y prácticamente acordado por los especialistas, de la magnitud absoluta e indicadores correspondientes sobre los nacimientos, defunciones y migración neta internacional (de carácter permanente) ocurridos durante los decenios 1950-1960, $1960-1970$ y $1970-1980$.

No obstante, estas evaluaciones no pueden considerarse per- 
fectas, pues existen niveles de incertidumbre en cuanto a la exactitud, por ejemplo, de las estimaciones realizadas sobre la migración internacional.

De cualquier forma y aunque difieren los resultados, en función de estos trabajos actualmente es posible conocer tanto el nivel aproximado de cobertura global de los últimos censos como las más precisas cantidades sobre el total de habitantes del país en $1950,1960,1970$ y 1980. Esto se muestra en el cuadro 1, donde se incluyen los resultados de las tres evaluaciones que sustentaron el establecimiento del punto de partida de las últimas proyecciones consideradas como oficiales. La primera, llevada a cabo en 1983 por especialistas del Conapo y del Centro Latinoamericano de Demografía [Celade], ${ }^{8}$ la segunda, básicamente desarrollada por técnicos del INEGI en $1985,{ }^{9}$ y la tercera, evaluación efectuada por personal del Conapo en 1989. ${ }^{10}$

De acuerdo con estas evaluaciones (véase el cuadro 1), la población total residente en el país a mediados de 1960 ascendió a poco más de 37 millones, entre 51.2 y 52.2 millones en 1970 y cerca de 69.5 millones el 30 de junio de 1980. Estas cantidades implican que los censos han tenido porcentajes globales de omisión decrecientes: entre $5.7 \%$ y $7.4 \%$ en 1960 , entre $4.5 \%$ y $6.3 \%$ en 1970 , $\mathrm{y}$ alrededor de $3.5 \%$ en 1980 .

Para terminar con esta sección conviene recordar que los anteriores porcentajes (o indicadores de la falta de cobertura de los censos) se refieren al país en su conjunto, que no se dispone de evaluaciones similares para entidades federativas, municipios o ciudades, y que para algunas de estas áreas y para 1980, por los problemas ya anotados de la definición de residentes usada en ese censo, los niveles de omisión seguramente fueron bastante superiores y en ciertos casos inclusive con signo negativo, es decir, manifestando sobreenumeración.

${ }^{8}$ El procedimiento seguido para realizar esta evaluación se encuentra en el mismo documento donde se publicaron las proyecciones (Véase INEGI, Conapo y Celade, 1983); pero una explicación más detallada de la evaluación se halla en Víctor García y Javier Pérez Astorga, 1985.

${ }^{9}$ Esta evaluación y sus resultados pueden consultarse en la Metodología de las proyecciones por entidades federativas: véase INEGI y Conapo, 1985. Asimismo, esta evaluzción se presenta en Ma. de la Paz López, 1986a, pero una exposición más minuciosa se encuentra en José Gómez de León y Virgilio Partida, 1986.

${ }^{10}$ El contenido y resultados de esta evaluación están incluidos en el documento donde el Conapo dio a conocer, en noviembre de 1989, las nuevas proyecciones de la población mexicana. Véase Conapo, 1989. 
CUADRO 1

Resultados de las evaluaciones sobre cobertura total de los censos de población mexicanos de 1950, 1960, 1970 y 1980

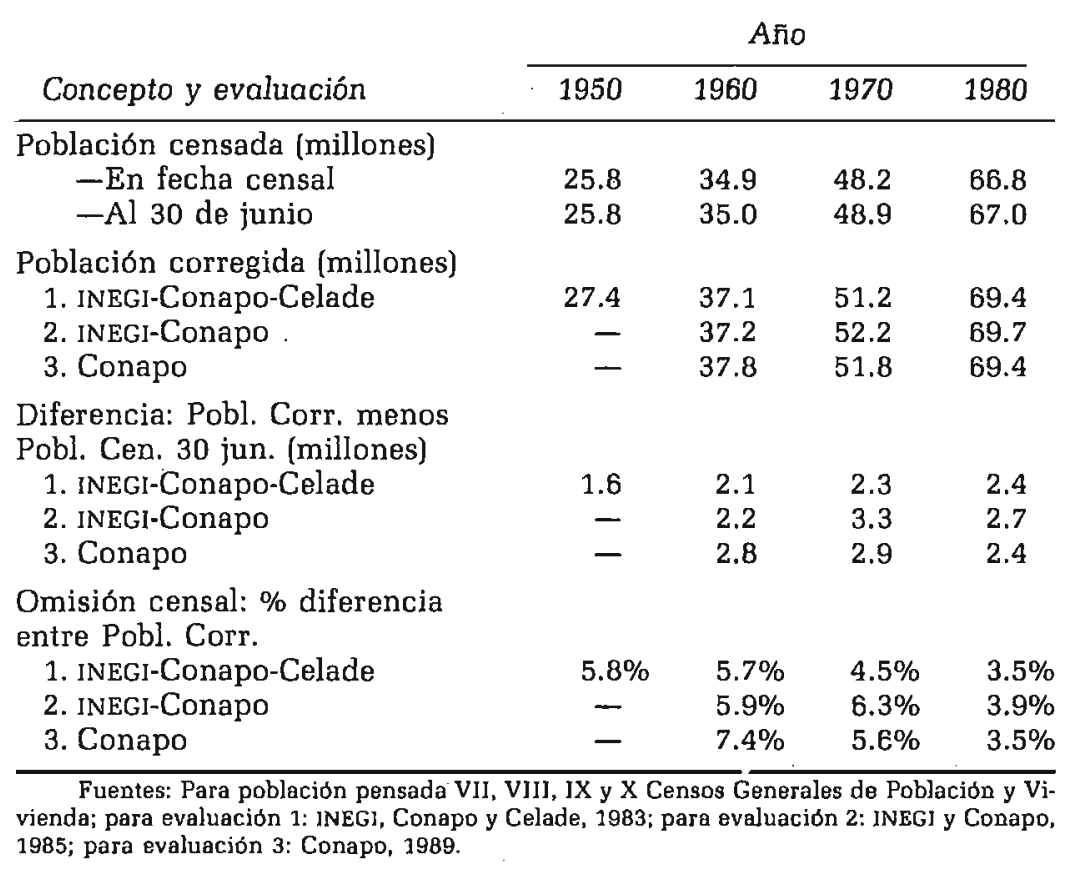

\section{Las cifras preliminares del censo de 1990}

El XI Censo General de Población y Vivienda fue levantado del 12 al 16 de marzo de 1990. Menos de cinco meses después, el 27 de julio del mismo año, se dieron a conocer sus resultados preliminares, ${ }^{11}$ que son datos sobre el total de habitantes de la República Mexicana clasificados por sexo y diferenciados según entidad federativa y municipio de residencia. ${ }^{12}$

Acerca de tales resultados se han suscitado muchas y muy diversas opiniones que más adelante se comentan; en lo que sigue

${ }^{11}$ Estos datos preliminares fueron dados a conocer en una conferencia de prensa del presidente del INEGI, y mediante la edición de un documento y un microdisco. Véase INEGI, 1990.

${ }^{12}$ Los datos de la población residente en el pafs se encuentran referidos al momento censal, que se estableció como las cero horas del día 12 de marzo de 1990. 
se señalan algunos puntos que directamente se refieren a estas primeras cifras y al trabajo desarrollado para obtenerlas.

\section{Oportunidad de los datos preliminares}

Para empezar debe resaltarse la rapidez con que fueron elaborados y puestos a disposición de todos los usuarios los resultados preliminares, los que además contienen un grado de detalle superior, pues los datos a nivel de municipio (por cierto de gran utilidad) no se habian presentado entre las primeras cifras de censos anteriores. ${ }^{13}$

Este innegable éxito de la etapa de difusión censal manifiesta además avances sustantivos en diversas actividades, como el control y revisión de los cuestionarios y la captura, codificación y procesamiento de los datos. Sin embargo, lo más relevante es que la prontitud del establecimiento de los resultados preliminares permite suponer que este censo va a lograr el cumplimiento de uno de sus tres objetivos fundamentales: "Alcanzar una producción oportuna de sus resultados". ${ }^{14}$

\section{Factibilidad de una evaluación}

En la etapa actual de desarrollo del censo de 1990 no es posible llevar a cabo una evaluación formal del mismo. Esto obedece, por un lado, a que los resultados disponibles son preliminares, y por otro, a que no se cuenta todavía con todos los datos y materiales necesarios para efectuar la evaluación censal.

Los resultados preliminares, más que impedir hacen improcedente una evaluación debido a su carácter de validez transitoria y aproximada en tanto se den a conocer las cifras definitivas. ${ }^{15}$ Este carácter es aceptado por las actuales autoridades del INEGI,

13 También en relación con la oportuna divulgación de los resultados preliminares, se encuentra la manifiesta disposición de las autoridades del INEGI para hacer aclaraciones sobre las cifras a quien lo solicite o tenga dudas al respecto. Véase, por ejemplo, El Heraldo de México, 3/VII/90, p. 1-A, y Unomásuno de la misma fecha (p. 2).

${ }^{14}$ Los otros dos objetivos básicos del XI Censo de Población son: lograr una mayor cobertura y mejorar la calidad de las respuestas, ambas respecto a los censos anteriores. Véase Ma. de la Paz López y Juan Manuel Herrero, 1988.

${ }^{15}$ Los funcionarios de] INEGI han declarado que los resultados definitivos se difundirán en julio de 1991. Véase Excélsior, 15/VIIJ/80, p. 3. 
quienes reconocen que los resultados definitivos tendrán variaciones, aunque estiman que no serán importantes o significativas. ${ }^{16}$

La magnitud de las diferencias entre datos preliminares y definitivos es imposible de ser prevista porque no se cuenta con información sobre el particular. ${ }^{17}$ No obstante, lo ocurrido al respecto en el censo de 1980 puede servir como referencia.

En esa ocasión se divulgaron tres conjuntos de resultados preliminares basados en una muestra de los cuestionarios aplicados el 4 de junio de 1980: los primeros dos conjuntos se difundieron en junio y diciembre del mismo año, ${ }^{18}$ y el tercero en 1981 con algunas variables a nivel de entidad federativa. ${ }^{19}$

A nivel nacional las modificaciones entre estos datos y los definitivos no fueron tan notables: $0.8 \%$ o $536 \mathrm{mil}$ personas como diferencia para el total de la población mexicana. Además, las variaciones pueden explicarse porque los primeros provienen de una muestra. ${ }^{20}$ Sin embargo, para algunos estados sí fueron sensibles los cambios en los números de sus habitantes, al punto de superar el grado estimado de omisión global del mismo censo (véase el cuadro 1); por ejemplo, las cifras preliminares de población total fueron mayores que las definitivas en $11.5,8.2,6.3$ y $6.3 \%$ respectivamente para Campeche, Tabasco, Oaxaca y Michoacán, y en más de medio millón de individuos para el Distrito Federal, y resultaron menores en 14 entidades, entre ellas Quintana Roo [7.0\%), Chihuahua [3.6\%] y Aguascalientes [3,1\%).

En lo que atañe a la ausencia en estos momentos de datos y materiales para una evaluación del censo de 1990, los puntos más importantes son los siguientes:

En primer término, y con independencia de la dimensión de sus modificaciones en el corto plazo, los resultados preliminares

16 Véase entrevista con el presidente del INEGI en la revista Siempre!, núm. 1939, año XXXVII, 22/VIII/93, pp. 72 y 73.

17 Conviene señalar que en las declaraciones de los funcionarios del INEGI y en el documento donde se publicaron los resultados preliminares no hay explicación sobre por qué éstos pueden diferir de los definitivos. Tampoco hay señalamientos respecto a cómo se establecieron las cifras preliminares. En la nota metodológica del documento (véase INEGI, 1990) sólo se expone la definición de población, indicando que se incluye una estimación de 343629 personas residentes de 114543 viviendas que no fueron censadas.

${ }^{18} \mathrm{El}$ primero de estos conjuntos de resultados preliminares (población total por sexo y entidad federativa) se difundió mediante una publicación: Secretaría de Programación y Presupuesto, VI/90.

${ }^{19}$ El tercer conjunto de datos preliminares se dío a conocer mediante una publicación: Secretaría de Programación y Presupuesto, 1981.

20 El total de población censada ascendió a 67382501 personas según los resultados preliminares, y a 66846833 individuos conforme a los datos definitivos. 
son insuficientes, pues sólo indican el total de población masculina y femenina de cada área de referencia. Para realizar una evaluación es imprescindible contar con las mismas cifras, pero clasificadas según ọtras variables, como edad y condición migratoria, a fin de llevar a cabo los análisis de consistencia interna y las confrontaciones con otros datos e indicadores (en particular los que dan cuenta de la fecundidad, mortalidad y migración), así como para estar en condiciones de aplicar los métodos y modelos demográficos diseñados para el efecto.

En segundo lugar se puede mencionar que aún no se dispone de todo el conjunto de estadísticas necesarias para ejecutar los contrastes y reproducir distintos escenarios de crecimiento demográfíco. Para este caso, como mínimo se requerirán las cifras de nacimientos y defunciones del decenio 1980-1990, los resultados del Censo de Estados Unidos de 1990 (sobre aspectos relativos a inmigración internacional) y los datos del Servicio de Inmigración y Naturalización de ese mismo país acerca de los migrantes mexicanos legales e indocumentados durante los años ochenta.

Finalmente, debe recordarse que para buscar indicaciones sobre la existencia y causas de posibles problemas de cobertura y calidad en los resultados de un censo, es inevitable contar con todo el material relativo a la planeación y puesta en práctica de las diversas etapas que conforman el trabajo censal. En la actualidad dicho material no se ha elaborado por completo, entre otras cosas porque todavía no se verifican algunas actividades y otras se encuentran en proceso.

En relación con este material resulta necesario mencionar que no basta con su existencia, pues además debe ser accesible a quienes utilizan el censo o desarrollan su evaluación. En tal sentido y tomando como base la explícita disposición de los directivos del INEGI para aclarar dudas (véase la nota 13), es posible que para el censo de 1990 hayan sido revisados estos materiales por especialistas ajenos a] INEGI, incluyendo aquellos documentos referidos a los problemas surgidos y las soluciones adoptadas al llevar a cabo las distintas tareas censales, como en el caso de las dificultades que, según algunos periodistas y sobre todo según declaraciones de distintos funcionarios (del propio INEGI entre ellos), se presentaron durante el levantamiento en varias partes (Quintana Roo y las ciudades de Coatzacoalcos, Tehuacán y Tijuana, por ejemplo) debido a la irresponsabilidad de los jóvenes enumeradores y sus desacuerdos en cuanto a remuneración. ${ }^{21}$

${ }^{21}$ Sobre estas dificultades véase El Sol de México, 3/VIII/90, p. 9 (para Quintana Roo); Proceso, núm. 718, 6/VIII/90, pp. 18-21 (para Coatzacoalcos); EI Finan- 
Para finalizar este apartado y también respecto al material, conviene señalar que ya se han efectuado algunas revisiones críticas de los documentos difundidos por el INEGI sobre el proceso censal, documentos referidos básicamente a su planeación y aspectos conceptuales. ${ }^{22}$ Asimismo, debe mencionarse que en tales revisiones se ha puesto de manifiesto que, por cuestiones conceptuales y deficiencias en el cuestionario, quizá el censo de 1990 presente problemas en la calidad de sus resultados definitivos, al menos en algunos temas como el de migración. ${ }^{23}$ Estas indicaciones, aunque parciales precisamente por la falta de todo el material censal y de cifras definitivas y con mayor desagregación, son suficientes para plantear la hipótesis de que este censo (como todo proceso de generación de estadísticas) puede tener errores, cuya magnitud y origen sólo podrán establecerse cuando se realice su evaluación integral.

\section{Sobre la exactitud del censo de 1990}

Aunque por lo dicho no es posible evaluar aún el censo de 1990, sí es factible, además de necesario, establecer algunos parámetros de referencia sobre la exactitud de sus resultados preliminares, al menos a nivel del país en su conjunto.

Para tener una idea de la ubicación del resultado preliminar del censo, de 81.1 millones de habitantes en México el 12 de marzo de 1990, en los siguientes párrafos se realiza, para llevar a cabo la comparación, un cálculo del rango donde muy probablemente se encuentre el verdadero número de todos los residentes en el país, utilizando para ello la simple relación denominada ecuación compensadora. ${ }^{24}$

ciero, 7/VIII/90, p. 26; Zeta de Baja California, 17-23/VIII/90, pp. 60A-64A (para Tijuana], y E] Universal, 5/IX/90, p. 2 [para el caso de Tehuacán).

22 Estos documentos son, entre otros, el cuestionario aplicado en el levantamiento, los manuales que se emplearon en la capacitación de los enumeradores, los trabajos expuestos en distintos foros por funcionarios del censo (véase $\mathrm{Ma}$. de la Paz López 1986b, por ejemplo) y el material presentado por el INEGI en reuniones especiales sobre el censo de 1990 (véase, por ejemplo, INEGI, 1987 y 1989).

23 Respecto a las revisiones críticas de los diversos aspectos y temas censales, pueden consultarse las ponencias presentadas en la Reunión sobre Análisis del Censo de 1990. Homenaje a Eduardo Cordero, que organizó la Sociedad Mexicana de Demografía del 30 de enero al 1 de febrero de 1989. En cuanto al tema de la migración, las seis ponencias al respecto presentadas en esa reunión, así como el trabajo de Rodolfo Corona (1990), especifican sus fallas y limitaciones.

24 Es decir, la población al final de un periodo es igual a la inicial, pero aumentada por los nacimientos en el intervalo, disminuida por las defunciones ocu- 
El punto de partida es la población a mediados de 1980, pues es la fecha más cercana para la cual se cuenta con una estimación confiable del total de habitantes. Tal estimación, que asciende aproximadamente a 69.5 millones (véase el cuadro 1), proviene de las más serias evaluaciones de la cobertura global del X Censo y, como se anotó, es el resultado de conciliar la dinámica demográfica mexicana entre 1950 y 1980 a través de los datos, los indicadores y los estudios existentes al respecto. ${ }^{25}$

En cuanto al crecimiento natural en la década 1980-1990 se tiene lo siguiente: por un lado y según los reportes del INEGI, en la República Mexicana ocurrió un promedio de 413000 fallecimientos anuales de 1980 a $1987 .{ }^{26}$ Pero teniendo en cuenta el subregistro de estos hechos, y según los análisis de la mortalidad prevaleciente en el país, se juzga que las defunciones de la década se hallan entre 4.5 y 5 millones. ${ }^{27}$

Por otra parte, las cifras de nacimientos durante el decenio oscilan desde alrededor de 25.4 millones de registrados según el INEGI y cerca de 26 conforme al Registro Nacional. de Población, ${ }^{28}$ hasta una cantidad próxima a los 22 millones en la década.

Esta última cantidad corresponde al supuesto de que se hubie-

rridas en el mismo e incrementada (o reducida) por el valor del saldo neto migratorio con el exterior del área bajo estudio.

25 Otro punto de referencia al respecto es que la estimación de 69.4 millones de residentes del país en 1980 (producto de la primera evaluación incluida en el cuadro 1) fue avalada y empleada en 1983 para el desarrollo de sus funciones por el Grupo Técnico Interinstitucional para la Estimaciôn de los Niveles de Fecundidad y Mortalidad, en el que participaron representantes tanto de instituciones académicas $[E]$ Colegio de México e Instituto de Investigaciones Sociales de la UNAM) como de organismos gubernamentales (Conapo, INEGI, Registro Nacional de Población, Secretaría de Salud e Instituto Mexicano del Seguro Social).

${ }^{26}$ Este promedio anual y el hecho de que las cifras de los ocho años considerados casi no difieren entre sí (el mayor valor es 433000 en 1980 y el menor 400000 en 1986), permiten suponer que los dos años aún sin datos definitivos tendrán cantidades similares al promedio, por lo que durante el decenio quedarán registrados alrededor de 4.1 millones de fallecimientos.

27 Sobre los análisis de mortalidad en México y el subregistro de fallecimientos pueden consultarse, por ejemplo, los estudios de Sergio Camposortega (1984) y de Rodolfo Corona y René Jiménez [1988).

28 En realidad ni el INEGI ni el Registro Nacional de Población (de la Secretaría de Gobernación) cuentan todavía con resultados definitivos para todo el decenio de los ochenta. Sin embargo y en cada caso por separado, los datos publicados para el periodo son bastante parecidos entre uno y otro año, por lo cual resulta razonable suponer que el promedio anual de la década será muy semejante a la media de nacimientos registrados en los años para los que se ha divulgado información definitiva. El promedio anual de nacimientos registrados asciende a 2.540 millones de 1981 a 1985 según el INEGI, y 2.607 millones de 1982 a 1986 según el Registro Nacional de Población. 
ran verificado, a partir de 1980, los descensos de la fecundidad que fueron establecidos en 1983 y 1985 mediante la fijación de valores sobre el comportamiento reproductivo de los mexicanos en el siguiente siglo. Tales valores se determinaron después de analizar la disminución de la fecundidad observada en los años setenta, pero sobre todo teniendo en cuenta las metas de crecimiento de la política demográfica mexicana. ${ }^{29}$

Sin embargo, el número de alrededor de 24 millones de nacimientos en el decenio es el que puede considerarse como el más cercano a la realidad. Esta apreciación se basa en que tal cifra se determinó a finales de 1989, con un método que incorpora indicadores más refínados y, sobre todo, después de analizar los datos de nacimientos registrados y los resultados de las principales cuatro encuestas sobre fecundidad que se realizaron entre 1976 y $1987 .^{30}$

Así pues, con los elementos anteriores se pueden adoptar números plausibles sobre el crecimiento natural en México durante el decenio: 5 millones de defunciones y 24 millones de nacimientos. Aunque también, y como límites extremos, conviene tener en cuenta las cifras de 25 y 22 millones de nacimientos.

Partiendo entonces de los 69.5 millones de habitantes en 1980 , al eliminar los decesos y agregar los nacimientos se obtienen tres cifras: $89.5,88.5$ y 86.5 millones de personas. Las mismas constituyen estimaciones de la población del país a mediados de 1990 , pero sin considerar el efecto de la migración internacional durante la década, siendo los 88.5 millones la cantidad más aceptable

29 El número aproximado de 22 millones de nacimientos entre mediados de 1980 y mediados de 1990 es el que corresponde a la denominada versión programática de las proyecciones oficiales de INEGI, Conapo y Celade de 1983 (22.682 millones) y a las versiones programática y alternativa de las proyecciones de INEGI y Conapo de 1985 (21.791 y 22.182 millones de nacimientos correspondientemente]. También en otros trabajos se estimaron cantidades parecidas empleando para ello criterios similares a los anotados, como la cifra de 22.404 millones de las Proyecciones de Población Urbana y Rural de Leopoldo Núñez y Lorenzo Moreno publicadas en 1986.

30 La cantidad cercana a los 24 millones de nacimientos entre 1980 y 1990 fue estimada en el Conapo al elaborar las proyecciones oficiales más recientes (véase Conapo, 1989). A las tres alternativas de estas proyecciones corresponden números similares al respecto: 24.066 millones en la hipótesis de fecundidad baja, 24.251 en la media y 24.491 millones de nacimientos en la hipótesis de fecundidad alta. Esta semejanza obedece a que la proyección de fecundidad no parte de 1980 , sino de 1985, que es el último año para el cual se analizó el comportamiento pasado de esta variable en función de las Estadísticas Vitales y de los indicadores de la Encuesta Nacional sobre Fecundidad y Salud que realizó la Secretaría de Salud en 1987. 
por lo dicho en relación con los 24 millones de nacimientos incluidos en su cálculo.

Para completar las anteriores estimaciones hace falta incluir el crecimiento social. En concreto, se requiere una medición de la migración internacional durante los años ochenta, pero referida a mediados del año 1990 y en términos de saldo neto migratorio. Además, sólo resulta indispensable trabajar con la migración permanente o definitiva (es decir, que implica el cambio de residencia hacia o desde el extranjero), en vista de que los desplazamientos temporales, compuestos básicamente por quienes van por épocas a trabajar a Estados Unidos, no afectan la cantidad de habitantes de nuestro país (que fue el objeto del levantamiento censal). ${ }^{31}$

Debe advertirse que la migración internacional es la variable más desconocida por la falta de estadísticas confiables al respecto, lo que se explica por las dificultades de su medición, las que se originan en algunos de los aspectos que para el caso de México caracterizan a este fenómeno, como la existencia de cruces de población sin documentos en ambas fronteras, el problema de la distinción del carácter temporal o permanente de muchos movimientos hacia y desde el extranjero, o las rápidas modificaciones en comportamiento y magnitud que puede sufrir el fenómeno ante cambios en la situación económica en general y en los mercados de trabajo en particular.

No obstante, existen al menos cuatro estimaciones que pueden servir de referencia. ${ }^{32}$ Una de ellas se realizó para analizar específicamente el fenómeno migratorio, ${ }^{33}$ mientras que las otras tres fueron llevadas a cabo para incorporar esta variable en sendas proyecciones de población. ${ }^{34}$

En lo general las cuatro estimaciones se elaboraron en dos pasos. El primero fue determinar, o "adoptar" de acuerdo con otros autores, una cantidad sobre el saldo neto migratorio internacional

${ }^{31} \mathrm{El}$ saldo neto (referido a 1990) de la migración internacional permanente ocurrida en el decenio es igual a los inmigrantes del periodo que sobrevivieron hasta mediados de 1990 , menos los correspondientes emigrantes.

32 En realidad se han elaborado más estimaciones. Sin embargo, muchas de ellas se basan en estadísticas referidas a 1970 y años previos: por ejemplo, la utilizada en las proyecciones de población oficiales de INEGl, Conapo y Celade de 1983 (véase Rodolfo Corona, 1982).

33 Ésta es la estimación de Manuel García y Griego [1989 a y b], quien, tomando en consideración sólo el intercambio poblacional entre México y Estados Unidos, calcula un saldo neto migratorio negativo para nuestro país y para los años ochenta de aproximadamente 1.8 millones de personas.

${ }^{34}$ Éstas son las que corresponden a las citadas proyecciones de INEGI y Conapo (1985), de Leopoldo Núñez y Lorenzo Moreno (1986), y Conapo (1989). 
del lustro 1975-1980. ${ }^{35}$ En cualquier caso, las estadísticas empleadas como base fueron datos de los censos de población de México y Estados Unidos de 1980 , así como información del Servicio de Inmigración y Naturalización de ese pafs. ${ }^{36}$ El segundo paso consistió en establecer para los dos quinquenios de los años ochenta la hipótesis de constancia del mismo saldo migratorio calculado para 1975-1980, o bien la hipótesis de que la intensidad de la migración apreciada entre 1975 y 1980 (en términos de tasas de migración neta) se mantiene en la década 1980-1990.

Por la elevada magnitud de la emigración a Estados Unidos los saldos netos calculados son negativos. La cifra más baja (saldo neto aproximado durante los años ochenta de -1.1 millones de personas) corresponde a la estimación usada en las proyecciones de INEGI y Conapo de 1985, donde se hizo el supuesto de igualdad de cifras en 1975-1980 y en los dos lustros siguientes. La cantidad más elevada, alrededor de -1.8 millones, es la que estimó García y Griego, quien tuvo en cuenta únicamente la migración entre México y Estados Unidos. Las otras dos estimaciones adquirieron valores intermedios: saldo migratorio internacional de la década cercano a -1.4 y -1.5 millones de individuos, según los trabajos de Núñez y Moreno (1986) y de Conapo [noviembre de 1989], respectivamente.

Estos saldos sugieren que posiblemente la migración internacional en los años ochenta provocó una pérdida de población residente próxima a 1.5 millones de personas. Al restar esta cantidad de las tres estimaciones de habitantes en México a mediados de 1990, que establecimos en función del crecimiento natural en el decenio, se obtienen (ya incorporado el crecimiento social) tres nuevas estimaciones sobre la población total del país para esa fecha: 88 millones la mayor, 87 la más plausible y 85 millones de re-

${ }^{35}$ El saldo neto migratorio de -854000 individuos, calculado para 1975-1980 por Robert Warren y Jeffrey Passel (1987), se utilizó directamente en la estimación de Manuel García y Griego y como uno de los insumos en las proyecciones de Conapo de noviembre de 1989. Específicamente para la proyección de INEGI y Conapo de 1985 se estableció el saldo neto del quinquenio 1975-1980 (véase J. Gómez de León y V. Partida, 1986, y V. Partida, s/f). Finalmente, en la proyección de Leopoldo Núñez y Lolenzo Moreno se utilizó el saldo para el mismo lustro determinado por P. Rowe (1982).

36 Al emplear estadísticas de México se considera en el análisis a los inmigrantes de cualquier parte del mundo, incluyendo mexicanos que retornan a vivir a la república. A] utilizar únicamente información de Estados Unidos se restringe la emigración internacional a la que ocurre a ese país. Esto último no afecta prácticamente las estimaciones, porque apenas el $1 \%$ de los emigrantes mexicanos viven en otros países (porcentaje calculado por José Gómez de León y Virgilio Partida, 1986). 
sidentes la menor (véanse los tres renglones iniciales de las cinco primeras columnas del cuadro 2).

Además de estas cantidades, desde mi punto de vista también se podría establecer otro conjunto de tres estimaciones: $86.5,85.5$ y 83.5 millones de personas, que serían el resultado de sustituir (en la operación del párrafo anterior) el valor del saldo neto migratorio del decenio, de -1.5 por otro de -3.0 millones (véanse los últimos tres renglones de las cinco primeras columnas del cuadro 2);

Esto implicarfa una situación extrema de emigración a Estados Unidos, pero que considero como límite a tener en cuenta por tres motivos, a saber:

i) Primero, que las cuatro estimaciones usadas como referencia se basan en cálculos de la migración en el quinquenio 19751980, cálculos que además suponen resueltos los problemas de medición de la migración de indocumentados. ${ }^{37}$

ii) Segundo, que al formular las hipótesis de que la migración cuantificada para 1975-1980 permanece durante los dos quinquenios subsiguientes (en números absolutos o relativos), no se tuvo en cuenta la historia del fenómeno de incrementos significativos entre los años sesenta y los setenta, como se aprecia al relacionar las cifras establecidas al respecto. ${ }^{38}$

iii) Tercero, pero de mayor relevancia, que al establecer las hipótesis del comportamiento migratorio para el periodo 1980-1990 no se incorporaron los posibles efectos en la magnitud del fenómeno de ciertos factores que surgieron en los años ochenta. Entre ellos se encuentra la crisis económica en México y sus secuelas

${ }^{37}$ Los datos de] Servicjo de Inmigración y Naturalización de Estados Unidos sobre localizaciones de mexicanos deportables contienen varios sesgos, como referirse a eventos y no a personas, y como medir al mismo tiempo la acción de la patrulla fronteriza. Sin embargo, sirven para indicar el orden de magnitud de la migración indocumentada, así como para tener una idea de las variaciones temporales. En este sentido conviene decir que estos datos ascendieron a $318000,3.808$ millones y 7.861 millones de mexicanos localizados deportables respectivamente para 1960-1966, 1970-1976 y 1980-1986 (cifras tomadas de Manuel García y Griego y Mónica Verea, 1988, pp. 118-121].

${ }^{38}$ Aun considerando el efecto de la mortalidad y el concepto de migración usado, en los mismos trabajos de Gómez de León y Partida (1986), Warren y Passel (1987) y Conapo (1989) se observa el aumento de la emigración: entre dos y tres veces mayor en los años setenta que en los sesenta. También como ejemplo se tiene el trabajo usado para las proyecciones INEGI-Conapo-Celade de 1983 (véase Corona, 1982), donde se calculo la migración neta del decenio 1960-1970, cuyo valor [ -700000 individuos] es cercano a la mitad de lo establecido en los tres estudios anteriores para la década 1970-1980. Finalmente, otros datos que no obstante sus fallas ilustran el aumento de la migración con el paso del tiempo son los que genera el Servicio de Inmigración y Naturalización sobre indocumentados devueltos a México [véase cifras en la nota 37). 
CUADRO 2

Rango de posibles niveles de omisión censal global de los resultados preliminares del XI Censo General de Población y Vivienda de 1990

\begin{tabular}{|c|c|c|c|c|c|c|c|}
\hline \multirow{3}{*}{$\begin{array}{l}\text { Alternativas de } \\
\text { crecimiento } \\
\text { poblacional } \\
\text { en la década } \\
1980-1990\end{array}$} & \multicolumn{5}{|c|}{$\begin{array}{l}\text { Estimación de población total residente } \\
\text { en México el } 30 \text { de junio de } 1990 \text { (millones) }\end{array}$} & \multicolumn{2}{|c|}{$\begin{array}{l}\text { Omisión censal factible } \\
=(P . \text { cen. })-(P \text {. estim. })^{2}\end{array}$} \\
\hline & \multirow{2}{*}{$\begin{array}{c}\text { Población } \\
\text { inicial } \\
1980\end{array}$} & \multicolumn{3}{|c|}{$\begin{array}{c}\text { Flujos demográficos } \\
1980-1990\end{array}$} & \multirow{2}{*}{$\begin{array}{c}\text { Población } \\
\text { final } \\
1990\end{array}$} & \multirow{2}{*}{$\begin{array}{c}\text { Personas no } \\
\text { enumeradas } \\
\text { en } 1990 \\
\text { (millones) }\end{array}$} & \multirow{2}{*}{$\begin{array}{c}\text { Nivel de } \\
\text { omisión censa } \\
(\%)\end{array}$} \\
\hline & & $\begin{array}{l}\text { defun- } \\
\text { ciones }\end{array}$ & $\begin{array}{l}\text { naci- } \\
\text { mientos }\end{array}$ & $\begin{array}{l}\text { migración } \\
\text { neta }\end{array}$ & & & \\
\hline \multicolumn{8}{|c|}{ Supuesto de emigración internacional baja } \\
\hline Hip. fecundidad baja & 69.5 & -5.0 & +22.0 & -1.5 & 85.0 & 3.4 & $4.0 \%$ \\
\hline Hip. fecundidad media & 69.5 & -5.0 & +24.0 & -1.5 & 87.0 & 5.4 & $6.4 \%$ \\
\hline Hip. fecundidad alta & 69.5 & -5.0 & +25.0 & -1.5 & 88.0 & 6.4 & $7.3 \%$ \\
\hline \multicolumn{8}{|c|}{ Supuesto de emigración internacional alta } \\
\hline Hip. fecundidad baja & 69.5 & -5.0 & +22.0 & -3.0 & 83.5 & 1.9 & $2.3 \%$ \\
\hline Hip. fecundidad media & 69.5 & -5.0 & +24.0 & -3.0 & 85.5 & 3.9 & $4.6 \%$ \\
\hline Hip. fecundidad alta & 69.5 & -5.0 & +25.0 & -3.0 & 86.5 & 4.9 & $5.7 \%$ \\
\hline
\end{tabular}

Fuente: Véase el apartado de este mismo texto, "Sobre la exactitud del censo de 1990", pp. 45 y ss.

1 La "población final" (en 1990) es igual a la "población inicial" (en 1980) menos las defunciones más los nacimientos y menos la migración neta internacional (cuyo saldo es negativo). Las poblaciones inicial y final están referidas al 30 de junio de 1980 y 1990 respectivamente. Las defunciones y los nacimientos son los ocurridos en esa misma década (de acuerdo con cada hipótesis); la migración internacional se refiere también al decenio, pero las cifras señalan migrantes permanentes sobrevivientes al 30 de junio de 1990.

${ }^{2}$ La omisión censal factible es la diferencia de la población estimada en cada hipótesis (o población final, en 1990) menos la cantidad de 81.6 millones de residentes en México, que equivale a trasladar al 30 de junio de 1990 el resultado preliminar de población censada del 12 al 16 de marzo del mismo año. Para cada hipótesis esta diferencia establece la cantidad de "personas no enumeradas", y el "nivel de omisión censal" es esta diferencia dividida entre la correspondiente población estimada (multiplicada por 100). 
en el deterioro del nivel de vida y la disminución de empleos, así como las consecuencias de la aplicación desde 1986 de la llamada Ley Simpson-Rodino que, además de legalizar la estancia en Estados Unidos de más de 2 millones de mexicanos indocumentados, ${ }^{39}$ ha provocado el incremento de la emigración, según lo sugieren estudios recientes sobre el tema. ${ }^{40}$ También puede mencionarse, como otro de estos factores, el cambio que parece tener el mismo fenómeno de emigración internacional en relación con mayor participación de mujeres y de personas con más elevada escolaridad en el flujo de mano de obra, superiores periodos de estancia en Estados Unidos de los trabajadores supuestamente temporales y un ingreso apreciable a la corriente migratoria de zonas del país distintas a las que tradicionalmente envían población al norte. ${ }^{41}$

Ahora bien, comparando tanto los tres valores de población en México a mediados de 1990 derivados de considerar un saldo migratorio decenal de -1.5 millones, como las tres estimaciones que suponen un saldo migratorio extremo de -3.0 millones, con la respectiva cifra preliminar del censo de 1990 (81.1 millones), pero trasladada al 30 de junio (81.6 millones de habitantes), resulta que esta última siempre es menor: $6.4,5.4$ y 3.4 millones de individuos o $7.3 \%, 6.4 \%$ y $4.0 \%^{42}$ para las primeras tres estimaciones, y 4.9 , 3.9 y 1.9 millones de personas o $5.7,4.6$ y $2.3 \%$ para los valores aso-

${ }^{39}$ La Ley de Reforma y Control de Inmigración (IRCA), o Ley SimpsonRodino, puesta en práctica a mediados de 1986, tuvo como uno de sus objetivos legalizar la permanencia en Estados Unidos de dos tipos de extranjeros sin documentos: uno, los que habían vivido en ese país desde 1982, y 2, aquellos trabajadores agrícolas que estuvieron empleados al menos 90 días en 1984, 1985 o 1986. Hasta mayo de 1990 se presentaron 1762143 solicitudes de legalización del primer tipo, siendo 1230457 de mexicanos, y 1276682 de] segundo tipo, siendo 1040268 de mexicanos (datos tomados de U.S. Immigration and Naturalization Service, 1990).

40 En relación con los efectos de la Ley Simpson-Rodino pueden consultarse, por ejemplo, las ponencias sobre el tema que se presentaron en el Seminario sobre la Migración Internacional en México: Estado Actual y Perspectivas, organizado por el Conapo en octubre de 1989, o bien los resultados de las investigaciones realizadas en México y Estados Unidos que financió la Comisión para el Estudio de la Migración Internacional, que fue creada en el Senado de Estados Unidos como parte de la propia Ley Simpson-Rodino (véase Commission for the Study of International Migration and Cooperative Economic Development, 1990a y 1990b).

${ }^{41}$ Existen varios trabajos donde se mencionan los cambios del fenómeno migratorio en los últimos años. Entre ellos se encuentran los citados en la nota anterior, así como los elaborados por los siguientes investigadores: Juan José Cantú (1990), Jorge Bustamante (1989) y Wayne Cornelius (1989, 1990a y 1990b).

42 Estos porcentajes se calcularon multiplicando por 100 , en cada caso, el cociente de la diferencia del dato censal (trasladado al 30 de junio) y la estimación, entre la propia estimación. 
ciados al saldo migratorio de -3.0 millones (estas cifras se presentan ordenadamente en las últimas dos columnas del cuadro 2).

Dado que los valores estimados representan el amplio rango de posibilidades de ubicación del verdadero número de habitantes del país a mediados de 1990 y que la cifra preliminar del censo (transportada a la misma fecha) se sitúa por debajo del mismo rango, las diferencias encontradas expresan, primero, que el censo no alcanzó a contabilizar a todos los mexicanos, y segundo, las probables cantidades de personas que quedaron al margen de la enumeración.

En el mismo sentido, los seis anteriores porcentajes podrían ser considerados como niveles globales de omisión del censo, cada uno en función, obviamente, del cumplimiento de los diferentes supuestos involucrados en la correspondiente estimación.

Los valores de estos posibles grados de omisión, entre 7.3 y $2.3 \%$, permiten hacer dos indicaciones. Por un lado, que difícilmente el censo de 1990 'ogró alcanzar el segundo de sus tres objetivos básicos, esto es, tener la mayor cobertura de la historia censal mexicana (véase la nota 14), objetivo que por cierto suponen cumplido en el INEGI, según se desprende de las declaraciones públicas de sus directivos. ${ }^{43}$ Sobre este particular conviene indicar que en las mismas declaraciones (como se verá más adelante) los funcionarios del INEGI hicieron públicas una serie de anomalías en el censo de 1980, al grado de descartar prácticamente sus datos publicados como punto de referencia. Tomando esto como base, los porcentajes de omisión censal que servirían para contrastar lo ocurrido en 1990 serían los calculados para el censo de 1970 (porque al eliminar el de 1980 resultan los de menor cuantía, véase el cuadro 1), que se hallan entre 4.5 y $6.3 \%$. De esta suerte, el censo de 1990 podría efectivamente cumplir con su propósito de ser el de mayor cobertura aun habiendo omitido hasta un $5 \%$ de residentes, que equivalen aproximadamente a 4.3 millones de habitantes.

Por otro lado, pero de mayor importancia, se encuentra el hecho de que ninguno de los anteriores seis porcentajes [véase el cuadro 2), entendidos como posibles niveles de omisión, manifiesta que el censo de 1990 (según sus resultados preliminares) podría tener graves problemas, sino que es un censo con cobertura total similar a los precedentes censos mexicanos, como se aprecia al contrastar estos porcentajes con los distintos grados de omisión

\footnotetext{
43 Véase, por ejemplo, El Nacional, 28/VII/90, pp. 1 y 27, y Proceso, núm. 718, 6/VIII/90, p. 18.
} 
calculados para los censos de 1950 a 1980 , que se exhiben en el cuadro $1 .{ }^{44}$

Los anteriores señalamientos en torno a la posible subcobertura del censo de 1990 a nivel nacional y de acuerdo con sus cifras preliminares, coinciden en buena medida con los resultados de los trabajos que recientemente elaboraron algunos especialistas. ${ }^{45}$ Mencionar la existencia de tales trabajos no sólo radica en que apuntan en el mismo sentido (el censo omitió una cantidad no despreciable de personas), sino que obedece al hecho de que emplearon procedimientos, datos y supuestos diferentes. ${ }^{46}$

Todas las observaciones y cálculos realizados en este apartado, cabe recordar, sólo se refieren al país en su conjunto. Desafortunadamente, resulta bastante más complicado [y rebasa los objetivos de este trabajo) establecer indicaciones sobre la cobertura del censo de 1990 para áreas geográficas menores (como estados, municipios o ciudades). Esto se debe a lo mencionado en la sección "Las evaluaciones de los censos mexicanos" respecto a las causas de la notable ausencia de evaluaciones para estos ámbitos espaciales, como la menor existencia de información estadística (que además contiene más errores), la necesidad de incorporar la migración interna (con su propia complejidad, cambios recientes y vinculaciones con las otras variables de la dinámica demográfica incluyendo la migración internacional), los problemas conceptuales del censo de 1980 y su incomparabilidad con los datos de. población total residente de otros censos, el de 1990 entre ellos, y la ausencia misma de evaluaciones y ajustes de censos previos a estos niveles espaciales, lo que se ilustra sin duda en las únicas

44 Puede decirse que también el INEGI considera la posibilidad de que el censo de 1990 contenga algunas fallas, como se desprende de la declaración de su presidente sobre el hecho de que no existen censos perfectos [véase El Heraldo de México, 15/VIII/90, p. 2), y como se aprecia en el reconocimiento directo de que el censo puede tener errores por parte del coordinador censal en Tehuacán, Puebla (véase El Universal, 5/1X/90, p. 2).

45 Estos trabajos fueron preparados para la mesa redonda sobre los Resultados Preliminares del Censo de Población y Vivienda de 1990. Consideraciones para su Análisis, organizada por la Sociedad Mexicana de Demografía y celebrada en El Colegio de México e] 5 de septiembre de 1990.

${ }^{46}$ Por ejemplo, Manuel Ordorica [1990) encuentra una omisión próxima al $8 \%$ o 7 millones de personas haciendo un análisis de las tasas de crecimiento demográfico entre los censos de 1960 y 1990; Sergio Camposortega (1990) estima una subcobertura en 1990 del orden del $7 \%$ con base en tasas de crecimiento natural y social en los últimos decenios; Beatriz Figueroa (1990), mediante un estudio de los registros de muertes y nacimientos de los años ochenta, establece distintas cifras de omisión posible, siendo la mayor de 9 millones de individuos; por último, y básicamente en función de sus propios estudios sobre migración internacional, Manuel García y Griego (1990) calcula una probable subcobertura de 4 por ciento. 
proyecciones oficiales a nivel de entidad federativa, donde las poblaciones iniciales de los estados fueron corregidas mediante el simple prorrateo de la estimación a nivel naciönal para 1980 (véase INEGI y Conapo, 1985)

\section{Los comentarios sobre el censo de $\mathbf{1 9 9 0}$}

A raíz de la divulgación de las cifras preliminares del censo de 1990 se han suscitado infinidad de comentarios sobre su exactitud, una muestra de los cuales fue difundida por la prensa. Al revisar los principales periódicos nacionales entre el 28 de julio y mediados de septiembre de 1990, encontramos alrededor de 100 artículos y declaraciones al respecto. ${ }^{47}$ De ellos, casi la mitad contienen declaraciones y opiniones (en su mayoría del presidente del INEGI) que tratan de mostrar el éxito del proceso censal y la elevada confiabilidad de sus resultados, mientras que otro $40 \%$ se dedica abiertamente a criticar y poner en tela de juicio dichas cifras. ${ }^{48}$ A continuación se presenta un breve análisis de estos dos conjuntos de artículos y declaraciones.

\section{Las críticas al censo}

Las críticas al censo han sido muy variadas. Las más precavidas simplemente expresan dudas, apuntando que los datos preliminares se prestan a especulación, son contradictorios, motivan la discusión y pueden tener errores. Otras indican con mayor precisión que los datos son bajos o reducidos, o que la población es mucho mayor, y otras más califican sin reserva alguna a los resultados censales como inexactos, absurdos, irreales, imposibles y falsos.

Los periodistas y los pocos académicos que han manifestado su opinión lo hicieron en forma cautelosa. En cambio, las críticas más severas provienen de miembros de partidos políticos de oposición y organizaciones empresariales, pero sobre todo de autori-

\footnotetext{
47 Los diarios consultados y el número de artículos en ellos incluidos fueron: Excélsior (16 artículos), La Jornada (13), E] Dia (12), El Nacional (11), El Sol de México (9), E] Universal (8), E] Heraldo de México (7), Unomásuno (7), E] Financiero (6) y Novedades (6), así como los semanarios Siempre!, Proceso y Zeta (de Baja California), con 2,2 y 1 artículos respectivamente.

${ }^{48}$ Hay además 12 artículos que directamente hablan del censo, pero sin contener opinión sobre la validez de sus datos.
} 
dades públicas, entre quienes sobresalen los presidentes municipales.

Esto se explica en buena medida por la supuesta relación de la cantidad de residentes con la distribución del presupuesto federal o el padrón electoral, cantidad de residentes que se determina con el censo y que resultó (de acuerdo con las cifras preliminares) notoriamente distinta a la esperada para algunos estados y municipios. Esto permite a su vez aclarar el porqué de la ubicación espacial de los más inconformes con el censo de 1990: básicamente ciudades cuyas expectativas en el número de sus habitantes quedaron muy por encima de los datos censales, como Ciudad Guzmán, Chetumal, Durango, Hermosillo, Jalapa, Ciudad Juárez, Mante, Mexicali, Nuevo Laredo, Pachuca, Poza Rica, Querétaro, San Juan del Río, Tampico, Tecate y Tijuana, y como las zonas metropolitanas de Guadalajara, ciudad de México y Monterrey.

En cuanto a la fundamentación de las críticas se pueden distinguir cinco grupos: i) los casos que cimentaron sus impugnaciones en la existencia de criterios políticos y no técnicos para establecer las cifras censales; ii) las críticas emitidas sin apoyo alguno, o bien tomando en cuenta la experiencia cotidiana o las impresiones personales sobre el crecimiento poblacional; iii) los juicios basados en el señalamiento de fallas durante el levantamiento censal, como omisión de viviendas y manzanas en el conteo e irresponsabilidad de los enumeradores; iv) las opiniones que se desprendieron de la comparación entre las cifras preliminares del censo y las cantidades establecidas en proyecciones de población, y $v$ ) las críticas que se basaron en las cantidades de habitantes que directa o indirectamente cuantifican otras estadísticas.

El primer grupo de estos argumentos trata aspectos ajenos a este trabajo; el segundo en realidad no sirve como punto de apoyo para desconfiar de los datos censales. El tercer conjunto de razones, en cambio, sí permite suponer omisiones y otros errores en el censo; sin embargo, para medir su efecto debe investigarse tanto la frecuencia y los lugares donde acaecieron los problemas de captación como las acciones del INEGI para detectarlos y resolverlos, lo cual formará parte de la evaluación censal cuando se disponga de los materiales correspondientes.

Los que fundamentaron sus opiniones señalando diferencias entre proyecciones de población y las cifras preliminares del censo deben separarse en dos partes, dependiendo del área geográfica de referencia; es decir, nivel nacional y zonas más pequeñas. Aquellos que usaron proyecciones a nivel entidad federativa, municipio o localidad no tomaron en cuenta los problemas, ya citados, que éstas tienen, en particular los derivados de la falta de 
comparabilidad conceptual del censo de 1980 para áreas geográficas menores y de los errores de ese censo al establecer y aplicar la definición de residentes habituales. En cambio, los que consideraron las proyecciones de la población total mexicana elaboradas en los años ochenta pusieron en juego los análisis más precisos sobre la evolución demográfica en las últimas décadas, incluyendo las mejores estimaciores de los residentes del país entre 1950 y 1980 (como se anotó en la sección "Las evaluaciones de los censos mexicanos").

Sobre este punto conviene indicar que las proyecciones a nivel nacional elaboradas en el pasado prácticamente determinaron la real población del siguiente momento censal (de acuerdo con las correcciones posteriores), estableciendo al mismo tiempo la subcobertura de ese siguiente censo. Esto se aprecia en forma clara al comparar las proyecciones más conocidas (y oficiales casi todas) que se efectuaron en los decenios 1960-1970 y 1970-1980 con las cantidades de población, censadas y corregidas, de los años 1970 y 1980 correspondientemente. En el cuadro 3 se muestra esta comparación, en la que destaca lo siguiente: primero, que en la década 1960-1970 se efectuaron dos proyecciones basadas en el censo de 1960; dadas sus distintas alternativas con ellas se calcularon cuatro cifras de población para 1970, todas cercanas a los 51 millones, cantidad que resultó superior en más o menos $4 \%$ respecto al dato censal de 1970 e inferior en $1.2 \%$ [ 1.8 o $2.0 \%$ ] a ese dato pero corregido posteriormente, y segundo, que en 1970-1980 se hicieron cuatro proyecciones a partir de 1970, obteniéndose (en función de sus diferentes hipótesis) 12 estimaciones de población total para 1980, las cuales variaron entre 69.9 y 71.9 millones de personas; ocho de tales estimaciones superaron el dato de población censada en 1980 en poco más de $4 \%$, resultando al mismo tiempo mayores en menos de $1 \%$ respecto de la corrección del propio dato censal, que se estableció ulteriormente.

En este cuadro 3 también se advierte el origen de las críticas de quienes se apoyaron en las proyecciones a nivel nacional. Es decir, en la década de los ochenta se llevaron a cabo tres proyecciones oficiales, basadas en la conciliación censal de 1960 a 1980 , como se indicó en la sección "Las evaluaciones de los censos mexicanos". Las siete estimaciones de residentes en todo el país para mediados de 1990 que de ahí se desprendieron, entre 85.8 y 89.0 millones, rebasan la cifra preliminar del XI Censo (81.6 millones de personas al trasladarse al 30 de junio de 1990) en un rango que va de 4.9 a 8.3 por ciento.

Por último, y en cuanto al quinto conjunto de críticas, las basadas en otra información, puede decirse que son insuficientes 
CUADRO 3

Comparación de población proyectada con la enumerada en el siguiente censo y con la corregida posteriormente

\begin{tabular}{|c|c|c|c|c|c|c|c|c|c|}
\hline \multirow{3}{*}{\multicolumn{2}{|c|}{ Tipo de población }} & \multirow{2}{*}{\multicolumn{4}{|c|}{$\begin{array}{c}\text { Población total residente } \\
\text { en México (millones) } \\
\text { Año (30 de junio) }\end{array}$}} & \multicolumn{4}{|c|}{ Diferencias $^{1}$} \\
\hline & & & & & & \multicolumn{2}{|c|}{$\begin{array}{l}\text { P. Proyectada } \\
\text { menos P. censada }\end{array}$} & \multicolumn{2}{|c|}{$\begin{array}{c}\text { P. Proyectada } \\
\text { menos P. corregida }\end{array}$} \\
\hline & & 1960 & 1970 & 1980 & 1990 & absol. & $\%$ & absol. & $0 \%$ \\
\hline \multicolumn{2}{|c|}{$\begin{array}{l}\text { Población censada (a jun. 30) } \\
\text { Población corregida }^{2}\end{array}$} & $\begin{array}{l}35.0 \\
37.4\end{array}$ & $\begin{array}{l}48.9 \\
51.7\end{array}$ & $\begin{array}{l}67.0 \\
69.5\end{array}$ & 81.6 & & & & \\
\hline \multicolumn{10}{|c|}{ Proyecciones 1960-1970 } \\
\hline $\begin{array}{c}\text { Z. Recchini, } \\
\text { Benitez } \\
\text { y } \\
\text { Cabrera }\end{array}$ & $\begin{array}{l}\text { Constante } \\
\text { Hipótesis } 2 \\
\text { Hipótesis } 3\end{array}$ & $\begin{array}{l}36.0^{*} \\
36.0^{*} \\
36.0^{*} \\
36.0^{*}\end{array}$ & $\begin{array}{l}50.7 \\
51.1 \\
51.1 \\
50.8\end{array}$ & & & $\begin{array}{l}1.8 \\
2.2 \\
2.2 \\
1.9\end{array}$ & $\begin{array}{l}3.6 \% \\
4.3 \% \\
4.3 \% \\
3.7 \%\end{array}$ & $\begin{array}{l}-1.0 \\
-0.6 \\
-0.6 \\
-0.9\end{array}$ & $\begin{array}{l}-2.0 \% \\
-1.2 \% \\
-1.2 \% \\
-1.8 \%\end{array}$ \\
\hline \multicolumn{9}{|c|}{ Proyecciones 1970-1980 } & $0.7 \%$ \\
\hline $\begin{array}{c}\text { Conapo } \\
1978\end{array}$ & $\begin{array}{l}\text { Histórica } \\
\text { Programática } \\
\text { Alternativa }\end{array}$ & & $\begin{array}{l}50.7^{*} \\
50.7^{*} \\
50.7^{*}\end{array}$ & $\begin{array}{l}70.1 \\
69.9 \\
69.9\end{array}$ & & $\begin{array}{l}3.1 \\
2.9 \\
2.9\end{array}$ & $\begin{array}{l}4.4 \% \\
4.1 \% \\
4.1 \%\end{array}$ & $\begin{array}{l}0.6 \\
0.4 \\
0.4\end{array}$ & $\begin{array}{l}0.9 \% \\
0.6 \% \\
0.6 \%\end{array}$ \\
\hline
\end{tabular}




\begin{tabular}{|c|c|c|c|c|c|c|c|c|}
\hline & Constante & $50.7^{*}$ & 71.9 & & 4.9 & $6.8 \%$ & 2.4 & $3.3 \%$ \\
\hline DGE & Hipótesis 1 & $50.7 *$ & 71.6 & & 4.6 & $6.4 \%$ & 2.1 & $2.9 \%$ \\
\hline 1978 & Hipótesis 2 & $50.7 *$ & 71.1 & & 4.1 & $5.8 \%$ & 1.6 & $2.3 \%$ \\
\hline & Hipótesis 3 & $50.7^{*}$ & 70.4 & & 3.4 & $4.8 \%$ & 0.9 & $1.3 \%$ \\
\hline & Constante & $50.7^{*}$ & 70.1 & & 3.1 & $4.4 \%$ & 0.6 & $0.9 \%$ \\
\hline Conapo & Programática & $50.7^{*}$ & 69.9 & & 2.9 & $4.1 \%$ & 0.4 & $0.6 \%$ \\
\hline 1979 & Alternativa 1 & $50.7^{*}$ & 69.9 & & 2.9 & $4.1 \%$ & 0.4 & $0.6 \%$ \\
\hline & Alternativa 2 & $50.7^{*}$ & 69.9 & & 2.9 & $4.1 \%$ & 0.4 & $0.6 \%$ \\
\hline Proyecciones & $0-1990$ & & & & & & & \\
\hline INEGI-Conapo & Programática & & $69.4^{*}$ & 86.2 & 4.6 & $5.3 \%$ & & \\
\hline Celade, 1983 & Alternativa & & $69.4^{*}$ & 89.0 & 7.4 & $8.3 \%$ & & \\
\hline INEGI-Conapo & Programática & & $69.7^{*}$ & 85.8 & 4.2 & $4.9 \%$ & & \\
\hline 1985 & Alternativa & & $69.7^{*}$ & 86.1 & 4.5 & $5.2 \%$ & & \\
\hline & Fecundidad alta & & $69.4^{*}$ & 87.8 & 6.2 & $7.1 \%$ & & \\
\hline Conapo & Fecundidad media & & $69.4^{*}$ & 87.6 & 6.0 & $6.8 \%$ & & \\
\hline & Fecundidad baja & & $69.4^{*}$ & 87.5 & 5.9 & $6.7 \%$ & & \\
\hline
\end{tabular}

Fuentes: cuadro 1 para poblaciones censada y corregida; y para las proyecciones véase la bibliografia.

1 Las diferencias se refieren a 1970 para proyecciones. 1960-1970; 1980 para prayecciones 1970-1980; y 1990 para proyecciones $1980-1990$

2 La población corregida en cada año es un promedio de los resultados de las tres evaluaciones mostradas en el cuadro 1.

* Las cifras con asterisco indican la población inicial de cada proyección. 
para sostener el juicio sobre la subcobertura censal, lo cual obedece, en el caso de algunas estadísticas (como las del censo de 1980, sobre todo a nivel de estados y municipios), a que contienen errores ya identificados aunque no siempre medidos y, la mayoría de las veces, a que los datos de referencia son parciales, no han sido evaluados y requieren de supuestos para convertirse en cantidades de población residente, supuestos cuyo intervalo de variabilidad factible rebasa los porcentajes de omisión que puede tener un censo. Tal es el caso, por ejemplo, de la matrícula escolar, de indicadores del crecimiento de la superficie urbanizada, del número de usuarios de agua o luz y de la cantidad de vehículos o líneas telefónicas.

En síntesis, las críticas al censo de 1990 difundidas por la prensa nacional se originan en su propia utilidad y en las aparentemente bajas cantidades de población que muestran sus resultados preliminares. La mayoría de las críticas carecen de validez por falta de elementos técnico-estadísticos que las sustenten. Sin embargo, buena parte de ellas deben tenerse en cuenta porque se basan en el señalamiento de fallas durante la captación de los datos censales, o bien en la subcobertura que implícitamente exhibe la contrastación entre los resultados preliminares y las proyecciones oficiales, las últimas de las cuales [o vigentes] calcularon una población total del país a mediados de 1990 de 87.5 a 87.8 millones de habitantes, que supera en cerca del $7 \%$ el resultado censal correspondiente: $\mathbf{8 1 . 6}$ millones al correr hacia mediados del año los 81.1 millones del 12 de marzo (véanse los tres renglones finales del cuadro 3 ).

\section{La propugnación del censo}

Los artículos que mencionan el éxito del censo y su elevada confiabilidad y que lo ubican como el de mejor cobertura, en realidad son reportajes elaborados con base en las declaraciones del presidente del INEGI, emitidas en las tres ocasiones en que se presentó ante los medios informativos para hacer comentarios al respecto, siendo la primera la presentación de las cifras preliminares. ${ }^{49}$

Los argumentos expuestos como sustentación de la calidad y exactitud del censo son de distinta naturaleza pero pueden clasificarse en dos grupos.

\footnotetext{
${ }^{49}$ En consecuencia, casi todos estos reportajes aparecieron al día siguiente de cada declaración; es decir, el 28 de julio de 1990, y el 3 y el 15 de agosto del mismo año.
} 
Por un lado se encuentran los señalamientos sobre el proceso mismo de generación de los datos censales. En otras palabras, indicaciones de que el censo tuvo éxito porque su planeación se inició en 1984, se simplificó el cuestionario, se amplió el periodo de levantamiento a cinco días, se eligió la mejor época para efectuar la captación, se realizó un detallado trabajo cartográfico, participaron de manera entusiasta más de 600000 voluntarios, se efectuaron tres visitas de campo (las dos primeras permitieron además conocer de antemano la cantidad de población), en materia organizativa el país se dividió en 30000 regiones, se descentralizaron tareas operativas y se utilizaron los equipos de cómputo electrónico y los sistemas de comunicación más modernos.

Desde mi punto de vista, sin embargo, estos señalamientos constituyen más bien explicaciones de cómo se diseñó y llevó a cabo el censo, cuyas acciones asociadas deben evaluarse para establecer si efectivamente lograron sus correspondientes propósitos o si fueron el origen de posibles fallas. Por ejemplo: seis años de planeación son en todo caso un compromiso; la simplificación del cuestionario provócó, al menos para el tema de la migración, la pérdida de comparabilidad con otros censos y con datos de encuestas, así como la reducción de su capacidad analítica y errores al plantear la pregunta (que con seguridad se reflejarán en la calidad de los datos resultantes); 50 la ampliación del periodo de levantamiento pudo ser contraproducente en razón de la inseguridad del día de la visita, combinado con ciertas situaciones prevalecientes hoy en México, como la ausencia en la vivienda de personas mayores de ambos sexos por cuestiones de trabajo; la ubicación del periodo de captación de datos quizá no fue del todo afortunada por ser época de intensos flujos migratorios estacionales (sobre todo en ciertas regiones] y por coincidir con la etapa del pago de impuestos; la participación de los encuestadores en algunas partes fue irresponsable y no entusiasta (y al parecer remunerada); la descentralización de tareas operativas y el uso de los procesadores más modernos del momento no salvaron al censo de 1980 de los problemas que tuvo, etcétera.

Por otra parte se hallan los argumentos dedicados a explicar las diferencias entre las cifras preliminares del censo y las cantidades de población mexicana que se habían estimado para 1990. Estos argumentos aludieron a tres aspectos: el carácter únicamente aproximado de los números que se calculan en las proyeccio-

50 Véase al respecto los documentos que fueron citados en la nota 23. 
nes, los errores de los datos del censo de 1980 y la existencia de fenómenos demográficos no considerados en las estimaciones.

En relación con las proyecciones se indicó que su nivel de incertidumbre aumenta con el paso del tiempo, que sus supuestos sobre crecimiento natural y social pueden no cumplirse, que no toman en cuenta desastres.naturales y que sus cantidades siempre resultan superiores a la realidad' Annque estos razonamientos sori en general acertados, no descalifican la utilidad de las proyecciones como referencia para tener una idea sobre la posible omisión de un censo, al menos a nivel nacional como se demostró en las dos décadas anteriores (véase el cuadro 3), sobre todo al recordar que las últimas proyecciones (Conapo, noviembre de 1989) tuvieron en consideración las estadisticas vitales de casi todo el decenio y los resultados de las encuestas demográficas efectuadas en 1982 y 1987.

Además, y como principal apunte respecto a lo falible de las proyecciones, se especificó que éstas no concuerdan con las cifras preliminares de 1990 porque se basaron en el censo de 1980, que tuvo diferentes errores. Esta argumentación no es atinada porque las proyecciones no parten de los datos censales sino de una corrección de los mismos, corrección que en el caso de las elaboradas en los años ochenta (por el propio INEGI y otros organismos] involucró los censos de 1950 a 1980 y las distintas estadísticas e indicadores sobre la acción de las variables demográficas en ese lapso.

En cuanto al censo de 1980 debe indicarse que incluirlo en estas justificaciones sobre la exactitud de las cifras preliminares de 1990 obedece a su empleo como base de las estimaciones de población, lo cual es al menos discutible por lo anotado en el párrafo anterior. En concreto y partiendo de la relación directa entre estimaciones y censo anterior, la argumentación expuesta fue que en el censo de 1980, ante problemas de cobertura, se usaron técnicas complementarias al propio levantamiento censal para estimar montos poblacionales, las cuales distaron mucho de ser exactas y provocaron en general la sobreestimación de los datos del total de residentes a nivel nacional, y en particular cantidades sobreestimadas de población para algunas entidades (como el Distrito Federal, Estado de México y Veracruz) y subestimadas en otras (como Oaxaca y Chiapas]. Además, se hizo referencia a que tales sobre y subestimaciones se detectaron en un análisis inicial efectuado por el INEGI y el Conapo, donde también se determinó que las tasas anuales de crecimiento total de la población mexicana ascendieron a $2.3 \%$ para $1980-1990$ y $2.9 \%$ para $1970-1980$. Se mencionó asimismo que ese análisis inicial será complementado con 
otro, inclusive ordenado por el presidente de la república, para revisar exhaustivamente los resultados del recuento de 1980 y establecer la exactitud de las estimaciones de hace 10 años, y que sólo ahora es posible evaluar la calidad de los ajustes realizados sobre el censo de 1980 dada la elevada precisión de los resultados del de 1990.

La anterior argumentación me parece del todo desafortunada, pues en vez de propugnar directamente los resultados del censo de 1990 intenta ubicar los posibles errores en otro proceso de generación de datos, incurriendo con ello en varias imprecisiones técnicas y agregando elementos que ponen en tela de juicio otras actividades del INEGI.

Entre las imprecisiones puede señalarse que, de ser correctos, los valores de las tasas de crecimiento poblacional manifiestan una subcobertura total del propio censo de 1990 superior a $5.5,{ }^{51}$ a menos que los censos de 1960 y 1970 hayan sido perfectos, el de 1980 sobreestimado en $3 \%$ y la dinámica demográfica de los años cincuenta distinta a la observada. ${ }^{52} \mathrm{O}$ también, que en el conjunto de la citada argumentación subyace una idea metodológicamente incorrecta del proceso de evaluación de una fuente de datos, que se manifiesta, por ejemplo, en tener que esperar una década para evaluar un censo, o en revisar la calidad de unos datos ya examinados en función de otros recién elaborados, aún no sujetos a evaluación y quizá preliminares.

Respecto a los elementos que se incorporaron y plantean desde mi perspectiva nuevos interrogantes, se encuentran los dictámenes implícitos sobre el rotundo fracaso de trabajos previos del

\footnotetext{
51 Suponiendo que hasta 1970 la dinámica demográfica del país en su conjunto era conocida y, como consecuencia, que el ajuste global del censo de 1970 fue correcto, esto es, de 48.9 a 51.7 millones, entonces al aplicar a esta última cantidad las tasas de crecimiento anual de 2.9 y $2.3 \%$ para los decenios $1970-1980$ y 1980-1990 se obtienen poblaciones a mediados de 1980 y 1990 de 68.8 y 86.4 millones, que resultan superiores a las correspondientes cifras censadas (trasladadas al 30 de junio) en $2.7 \%$ (para 1980) y $5.9 \%$ (para 1990).

52 Partiendo del dato censal de 1970 (48.9 millones al 30 de junio) y empleando las tasas anuales de $2.9 \%$ para $1970-1980$ y $2.3 \%$ para $1980-1990$, se obtiene aproximadamente la cifra preliminar del censo de 1990 [81.6 mil]ones a mediados de año), así como una cantidad de 65.0 millones para 1980. Esta operación implica entonces: primero, que la enumeración en 1990 fue sin omisión y que las tasas señaladas por el INEGI son correctas; segundo, que el censo de 1980 sobreenumeró 2 millones de personas, y tercero, que a partir del dato censal de 1970, este censo se supone perfecto, con lo cual, además, la conocida dinámica demográfica de los anos sesenta resulta errónea, o bien, tal dinámica ha sido cuantificada en forma precisa pero el censo de 1960 no tuvo fallas de cobertura, lo que provoca que el crecimiento poblacional de los años cincuenta fue distinto al observado.
} 
mismo INEGI y del Conapo, como las proyecciones de población, las evaluaciones de censos anteriores y las supuestas mejoras de las estadísticas vitales. $\mathrm{O}$ bien, el hecho de que un análisis inicial (elaborado seguramente en unos cuantos días) permita determinar la dinámica poblacional de dos decenios a nivel de entidad federativa.

Sin embargo, lo que considero de mayor importancia es que sólo ahora, al cuestionarse el censo de 1990, se dé a conocer que los datos del censo anterior son estimaciones de montos poblacionales y no producto del levantamiento de información. Esto es importante no porque se hayan realizado modificaciones a las estadísticas originales, sino porque tales manejos se hayan ocultado durante diez años, teniendo en su transcurso diversas oportunidades especialmente adecuadas para el efecto, como la difusión de las evaluaciones del censo llevadas a cabo por el propio INEGI y las mismas publicaciones de los datos censales (algunas de las cuales se hicieron ya iniciada la planeación del censo de 1990).

Finalmente, el tercero de los aspectos mencionados al tratar de explicar las diferencias entre las cifras preliminares de 1990 y las estimaciones sobre población para este año (el que alude a otros fenómenos demográficos no contemplados por estas últimas), es el que resulta de mayor apoyo para el censo o, mejor dicho, de justa crítica a las proyecciones, en particular para aquellas referidas a un ámbito geográfico diferente al nacional. Las indicaciones al respecto fueron que hubo un reacomodo poblacional en los años ochenta, se crearon nuevos polos de desarrollo, el Distrito Federal ha tenido un cambio en el uso del suelo, se dio un proceso de descentralización demográfica y las ciudades medias crecieron apreciablemente; es decir, que el fenómeno migratorio se manifestó de forma distinta a lo previsto en las estimaciones.

En suma y salvo la referencia a movimientos migratorios que pueden explicar en parte las diferencias entre los resultados preliminares y las cantidades estimadas de residentes en algunas ciudades, me parece que las declaraciones en apoyo al éxito del proceso censal no disiparon las dudas existentes en torno a su cabal exactitud.

\section{Comentarios finales}

A lo largo del trabajo se hicieron distintos señalamientos en relación con la confiabilidad del XI Censo de Población de 1990; lòs tres siguientes pueden considerarse como los más relevantes:

1) Por el momento no es factible proporcionar un dictamen 
definitivo sobre la exactitud del censo. Esto se debe, entre otras cosas, a que no se dispone todavía de todos los documentos que es necesario revisar acerca de las diversas actividades censales, y a que únicamente se han producido resultados preliminares sujetos a modificación, los cuales además no contienen el grado de detalle requerido para su formal evaluación.

2) No obstante lo anterior, la contrastación del total de población censada en el país (según las cifras preliminares), con otras estadísticas e indicadores, con diversas estimaciones y proyecciones y en general con el conocimiento que se tiene sobre la dinámica demográfica mexicana de los últimos años, permite establecer la plausible hipótesis de que el censo de 1990 omitió en su conteo a un número que se halla en el intervalo aproximado de 2 a $6 \mathrm{mi}$ llones de personas.

3) Por último, que esta posible subcobertura (aun en caso de verificarse la más elevada) no descalifica el proceso censal de 1990, ni inutiliza sus datos, pues los porcentajes de omisión implícitos en el anterior intervalo ( 2.4 a $6.8 \%$ ) se hallan dentro del rango de subcobertura de los anteriores censos realizados en México.

\section{Bibliografia}

Benítez, Raúl y Gustavo Cabrera (1966). Proyecciones de la población de México. 1960-1980. Banco de México S.A., 247 pp.

Bustamante, Jorge A. (1989). "Medición del flujo de inmigrantes indocumentados", en Bustamante y Cornelius [coord.], Flujos migratorios mexicanos hacia Estados Unidos. México, Fondo de Cultura Económica, pp. 115-131.

Camposortega, Sergio (1984). Estado actual del conocimiento sobre los niveles y tendencias de la mortalidad en México, México, Conapo, 43 pp. (1990). "Consistencia e inconsistencia entre fuentes de datos en las estimaciones de población", ponencia presentada en la mesa redonda "Los Resultados Preliminares del Censo de 1990", México, Sociedad Mexicana de Demografía, 5 de septiembre.

Cantú, Juan José (1990). "Continuidad y cambio en ciertos patrones migratorios en el plano nacional", ponencia presentada en la "IV Reunión Nacional de Investigación Demográfica en México", México, Sociedad Mexicana de Demografía, abril, $23 \mathrm{pp}$.

Celade (1976). América Latina: situación demográfica y perspectivas para el año 2000, Santiago de Chile, $53 \mathrm{pp}$.

Commission for the Study of International Migration and Cooperative Economic Development 1987-1990 (1990a). Unauthorized Migration: Addressing the Root Causes. Research Addendum, volume I, U.S. Government Printing Office, $624 \mathrm{pp}$. 
(1990b). Unauthorized Migration: Addressing the Root Causes. Research Addendum; Supplement, U.S. Government Printing Office, 298 pp.

Conapo (1978). México demográfico. Breviario 1978, México, 70 pp. (1979). México demográfico Breviario 1978, México, 127 pp.

(1989). Proyecciones de la población de México, 1980-2025, México, noviembre, $81 \mathrm{pp}$. (inédito).

Cornelius, Wayne (1989). "La demanda de fuerza de trabajo mexicana en Estados Unidos", en Bustamante y Cornelius (coord.), Flujos migratorios mexicanos hacia Estados Unidos, México, Fondo de Cultura Económica, pp. 39-66.

(1990a). "Labor Migration to the U.S.: Development Outcomes and Alternatives in Mexican Sending Communities", San Diego, University of California, $166 \mathrm{pp}$. (edición revisada del 14 de marzo). (1990b). "Los migrantes de la crisis: el nuevo perfil de la migración de mano de obra mexicana a California en los años ochenta", en Gail Mummert (ed.), Población y trabajo en contextos regionales, México, El Colegio de Michoacán, pp. 103-141.

Corona, Rodolfo (1982). "Estimación de la emigración definitiva de mexicanos a Estados Unidos en la década 1960-1970", en Revista de Estadística y Geografia, vol. 2, núm. 7, México, pp. 7-24. (1986). Evaluación de los datos censales de 1980. Población residente y migración en Baja California, Tijuana, Centro de Estudios Fronterizos del Norte de México, $172 \mathrm{pp}$.

(1988). Evaluación conceptual y numérica de la información sobre migración del censo de población de 1980, México, UNAM, Centro Regional de Investigaciones Multidisciplinarias, $64 \mathrm{pp}$.

(1990). "La medición del fenómeno migratorio en el Censo de Población de 1990", en Frontera Norte, vol. 2, núm. 3, México, El Colegio de la Frontera Norte, pp. 5-30.

A. Minujin y G. Vera (1982). Manual de técnicas de evaluación y ajuste de información estadística, México, Fondo de Cultura Económica, $290 \mathrm{pp}$.

y René Jiménez (1988). El comportamiento de la mortalidad en México por entidad federativa, 1980, México, UNAM, Centro Regional de Investigaciones Multidisciplinarias, $133 \mathrm{pp}$.

Dirección General de Estadística (DGE) (1978). Proyecciones de la población mexicana 1970-2000 (Nivel nacional), México, Secretaría de Programación y Presupuesto, $65 \mathrm{pp}$.

Figueroa, Beatriz (1990). "El crecimiento natural y la población esperada en 1990", ponencia presentada en la mesa redonda "Los Resultados Preliminares del Censo de 1990", México, Sociedad Mexicana de Demografía, 5 de septiembre.

Garcia y Griego, Manuel (1990). "La oferta de emigrantes mexicanos a Estados Unidos, 1990-2010: análisis demográfico", México, El Colegio de México, $87 \mathrm{pp}$. (inédito).

(1989b). "La oferta de emigrantes mexicanos a Estados Unidos, 1990-2010", en Bustamante y Cornelius (coord.), Flujos 
migratorios mexicanos hacia Estados Unjdos, México, Fondo de Cultura Económica, pp. 67-114.

(1990). "La emigración de mexicanos a Estados Unidos 1980-1990 y las cifras censales de 1990", ponencia presentada en la mesa redonda "Los Resultados Preliminares del Censo de 1990", México, Sociedad Mexícana de Demografía, 5 de septiembre.

y Mónica Verea [1988). México y .Estados Unidos frente a Ja migración de indocumentados, México, Miguel Ángel Torrúa Editor, UNAM, $174 \mathrm{pp}$.

García, Víctor y Javier Pérez Astorga (1985). "Un ejercicio de conciliación intercensal”, en Revista de Estadística y Geografía, vol. IV, núm. 13, México, INEGI, pp. 1-15.

Gómez de León, José y Virgilio Partida (1986). "Estimación del grado de cobertura en los censos de población de México 1960, 1970, 1980", en INEGI, pp. 1510-1552.

INEGI (1986). Memoria: Taller Nacional de Evaluación del Censo General de Población y Vivienda, 1980, México, vol. 1, pp. 1-1106; vol. 2, pp. 1107-2182.

[1987). Propuesta de diseño conceptual para el censo piloto, México, junio, $117 \mathrm{pp}$.

[1989]. Propuesta del cuestionario para el XI Censo General de Población y Vivienda de 1990, documento presentado a la Reunión sobre Análisis del Censo de 1990: Homenaje a Eduardo Cordero, México, Sociedad Mexicana de Demografía, 30 de enero al primero de febrero, $65 \mathrm{pp}$.

(1990). Resultados preliminares XI Censo General de Población y Vivienda, 1990, México, $285 \mathrm{pp}$.

Conapo y Celade (1983). México: Estimaciones y proyecciones de población 1950-2000, México, $36 \mathrm{pp}$.

y Conapo (1985). Proyecciones de la población de México y de las entidades federativas: 1980-2010, México, $134 \mathrm{pp}$.

López, Ma. de la Paz (1986). "Cobertura y mala declaración en el X Censo General de Población y Vivienda 1980", en INEGI y Celade, Memoria: Taller Interamericano de Evaluación de Censos de Población y Vivienda, México, pp. 387-420.

(1986). "La planificación del Censo de Población y Vivienda de 1990", ponencia presentada en la III Reunión Nacional sobre Investigación Demográfica en México, México, Sociedad Mexicana de Demografía, noviembre, $26 \mathrm{pp}$.

y Juan M. Herrero (1988). "Hacia el Censo de Población y Vivienda de 1990", en Demos, Carta Demográfica sobre México, pp. 31-32.

Núñez, Leopoldo y Lorenzo Moreno (1986). México: Proyecciones de población urbana y rural 198c-2010, México, Academia Mexicana de Investigación en Demografía Médica, $120 \mathrm{pp}$.

Ordorica, Manuel (1990). "Reflexiones en torno a los resultados preliminares del Censo de 1990", ponencia presentada en la mesa redonda "Los Resultados Preliminares del Censo de 1990", México, Sociedad Mexicana de Demografía, 5 de septiembre. 
Partida, Virgilio (s/f). "Estimación de la migración neta internacional 1960-1980", en J. Martínez, Población de México a fines del siglo XX, México, IMSs, pp. 29-43.

Recchini, Zulma (1963). Proyección de la población de México por sexo y grupos de edades: 1960-1980. Chile, Celade.

Rowe, P. (1982). Detailed Statistics on the Urban and Rural Population of Mexico: 1950 to 2010, Washington, International Demographic Data Center, U.S. Bureau of the Census.

Secretaría de Programación y Presupuesto (1980). Imágenes de los censos de población y vivienda, México, junio, $167 \mathrm{pp}$.

(1981). X Censo General de Población y Vivienda, 1980. Resultados preliminares a nivel nacional y por entidad federativa, México, $97 \mathrm{pp}$.

U.S. Immigration and Naturalization Service (1990). "Provisional Legalization Application Statistics. May 16, 1990", U.S. INS Statistics Division. Office of Plans and Analysis, $13 \mathrm{pp}$.

Warren, Robert y Jeffrey Passel (1987). "A Count of the Uncountable: Estimates of the Undocumented Aliens Counted in the 1980 United States Census", en Demography, vol. 24, núm. 3. 